\title{
Langerhans Cell Histiocytosis; Managing an Uncommon Condition in Pregnancy and Labor: A Case Report
}

\author{
Inês Martins (iD ${ }^{1,}$, Mafalda Amorim Castro ${ }^{1}$, Daniel Vieira ${ }^{1}$ and Ana Raimundo ${ }^{1}$ \\ ${ }^{1}$ Centro Hospitalar e Universitario de Coimbra EPE, Coimbra, Portugal \\ "Corresponding author: Centro Hospitalar e Universitario de Coimbra EPE, Coimbra, Portugal. Email: ines.iqm@gmail.com
}

Received 2020 October 05; Revised 2020 December 04; Accepted 2020 December 28.

\begin{abstract}
Introduction: Langerhans cell histiocytosis (LCH) is a rare heterogeneous disease that normally occurs in children under 15 years but can rarely be diagnosed in adulthood. It can affect any organ of the body, and a less favorable prognosis is expected when either liver, lung, spleen, or bone marrow are affected. Diabetes insipidus, from pituitary dysfunction, is one of the most common consequences that can develop anytime during the disease, and symptoms normally worsen during pregnancy. Pregnancy with this disease is uncommon, and when it occurs, a cesarean section is normally performed.

Case Presentation: We report a 34-year-old pregnant woman (37 weeks and two days gestation) with the diagnosis of a disseminated LCH at the age of 30 who presented herself at the obstetrics emergency department due to respiratory distress. During pregnancy, her pulmonary function remained stable, and she was asymptomatic until the last two days before she was admitted. Labor was induced, with vaginal misoprostol, to achieve a vaginal birth with epidural analgesia. The child was born without complications, and the patient had an immediate clinical improvement. In the following three months, she remained asymptomatic without any worsening of her disease.

Conclusions: In LCH, a cesarean section is the first choice in many cases due to pulmonary impairment. We concluded that early placement of an epidural catheter allows labor analgesia while safeguarding the possibility of an epidural anesthesia in case of urgent/emergent cesarean section. If pulmonary function remains stable, vaginal delivery is possible, thereby being less invasive and allowing for a faster recovery.
\end{abstract}

Keywords: Langerhans Cell Histiocytosis, Pregnancy, Epidural Analgesia, Parturition

\section{Introduction}

Langerhans cell histiocytosis ( $\mathrm{LCH})$ is a rare disease, which normally occurs in children under 15 years (4 - 5 cases per million per year) but can rarely be diagnosed in adulthood ( 1 - 2 cases per million per year) (1-3). LCH is a clonal dendritic cell disease, which can affect any organ of the body. Normally, when the liver, lung, spleen, bone marrow, or central nervous system (CNS) are affected, a less favorable prognosis is expected. Diabetes insipidus (DI) due to pituitary dysfunction is one of the most common consequences that can develop anytime during the course of the disease (4).

As patients with LCH normally do not survive until adulthood, pregnancy with this disease is even more uncommon and unpredictable, requiring cesarean section in many selected cases due to pulmonary decompensation and dyspnea (especially after 32 weeks of gestation) (5). We present the case of a patient with an adult diagnosis of a disseminated LCH (lung, endocrine, liver, and bone involvement), pregnant with her second child (her first child after her LCH diagnosis) that even though she had moderate respiratory distress because she was multiparous, it was decided to induce labor to avoid an unnecessary cesarean section.

\section{Case Presentation}

A 30-year-old Caucasian woman was followed by a pneumologist due to an insidious dyspnea on exertion and even when resting. She had been a smoker for 18 years (30 pack-years) and had her first child at the age of 20 as a vaginal delivery. There was no history of any chronic medication intake or any prior drug or food allergies.

Her disease was monitored thoroughly and, initially, through a lung CT scan, several cysts were identified, suggesting bullous emphysema associated with fibrosis in the lower lobes. In the meantime, the patient developed 
polyuria and polydipsia (with the consumption of more than 5 liters of water per day), so, as her anti-diuretic hormone levels were low, $\mathrm{LCH}$ was considered a possible diagnosis, and intranasal desmopressin was administered with symptomatic improvement. A lung biopsy was performed without any complications, and LCH diagnosis was confirmed through the expression of CD1a and S100 protein.

As the patient had developed symptoms of a diabetes insipidus, a cranial magnetic resonance was performed that confirmed the existence of a lesion located in the posterior lobe of the pituitary gland. Finally, a positron emission tomography was performed, which revealed diffused liver and skeletal lesions besides the pulmonary and pituitary lesions. So, the patient was diagnosed with a disseminated $\mathrm{LCH}$, and she was followed closely in the rare disease consultation and was started on cytarabine (5-day treatment every month for one year) with significant improvement in respiratory distress and dyspnea. Pulmonary function tests (PFT) were repeated yearly and showed a mixed pattern that remained stable during follow-up. Afterward, the patient manifested the will to have another child so, she was followed at the high-risk pregnancy consultation and became pregnant 14 months after the last treatment with cytarabine.

Her pregnancy progressed normally, without any complications or symptoms, and in terms of medication she was only taking iron and folic acid besides her usual dose of desmopressin (2 nasal sprays every morning, $20 \mu \mathrm{g}$ daily) associated with a water restriction of about 750 $\mathrm{ml} /$ day that the patient managed according to her urine output.

At her 28th week of gestation, she began to feel tired and had to increase the desmopressin dosage to a total of 40 micrograms daily divided into two doses due to overwhelming polydipsia. Her PFT and carbon monoxide diffusing capacity (DLCO), which were stable for her whole pregnancy, were at this time slightly worse (Table 1).

At 37 weeks and 2 days of pregnancy, the patient presented to the emergency department due to unbearable dyspnea that made it impossible to perform any type of effort. She had no painful contractions or other evidence of being in labor. At the obstetric evaluation, the patient had a firm cervix with a $3.5 \mathrm{~cm}$ dilation. The fetus had a cephalic presentation and showed no signs of distress. As the patient's symptoms were worsening, labor was induced using misoprostol, and she was brought to the delivery room. An arterial blood gas test performed at that moment showed a respiratory alkalosis $\left(\mathrm{pH}=7.47, \mathrm{paO}_{2} 90.6\right.$ $\mathrm{mmHg}$, and $\mathrm{paCO}_{2} 29.3 \mathrm{mmHg}$ ) with an oxygen saturation of $96 \%$. She was monitored, and oxygen was administered at a flow of 2 liters/minute through nasal prongs.

An epidural catheter was placed at the L3-L4 interspace preventively to facilitate the administration of analgesia when labor began or, in the worst-case scenario, if there was a need for epidural anesthesia if a cesarean section had to be performed. A bolus of $15 \mathrm{mg}$ of ropivacaine and 10 $\mu \mathrm{g}$ of sufentanil were administered, and an anesthetic sensory bilateral T10 block was successful after testing. Ropivacaine $(0.2 \%)$ was then administered continuously. The patient was stable, and the expulsive phase began 2 hours after arriving at the delivery room and lasted only 20 minutes. Although forceps had to be used to progress the labor, there were no further complications during this procedure. The baby was born with $3.07 \mathrm{~kg}$ with normal APGAR scores. Respiratory symptoms reverted completely 12 hours after labor, and the patient was admitted to the ward without dyspnea. She was discharged three days later.

The patient was re-evaluated three months after childbirth and did not present any symptoms of polyuria or polydipsia (with her usual desmopressin dose) or any sort of respiratory distress. Her PFT had improved to her previous stable values before pregnancy.

\section{Discussion}

Since LCH is such a rare disease in adult patients, there are no guidelines in the current literature that concern management during pregnancy and labor in women with a disseminated disease (4). These patients not only present with a worse prognosis but also have a higher risk of complications and deterioration of pulmonary function in the final weeks of gestation. Previous studies have also discussed that during pregnancy, patients with LCH and Diabetes Insipidus become more symptomatic with polyuria and polydipsia probably due to a degradation of the administered desmopressin by placental enzymes (6). There are no guidelines on water restriction in pregnant patients, so the patient was expected to manage her own water intake according to her urine output, which was normally $750 \mathrm{~mL} /$ day.

There are no studies that associate the disease itself with a decrease in fertility, but in this case, as the patient had been treated with cytarabine, she was more likely to be infertile, thus making pregnancy in this patient even more uncommon possibility (7).

Normally, in patients with LCH, cigarette smoking seems to make pulmonary dysfunction more marked. Cessation of smoking is mandatory because the most important factor in pulmonary dysfunction in those with pulmonary LCH is the continuation of smoking (8). In our 


\begin{tabular}{|c|c|c|c|c|c|c|}
\hline & Predicted Value & $\begin{array}{c}\text { 1st Test After } \\
\text { Diagnosis }\end{array}$ & 14 Weeks Gestation & 28 Weeks Gestation & During Labor & $\begin{array}{l}3 \text { Months After } \\
\text { Delivery }\end{array}$ \\
\hline FEV1 (L) & 3.20 & 2.76 & 3.21 & 2.70 & & 2.39 \\
\hline FVC $(L)$ & 3.84 & 3.50 & 3.84 & 3.65 & & 3.46 \\
\hline $\operatorname{TLC}(\mathrm{L})$ & 5.03 & 4.50 & 4.61 & 4.69 & & 4.48 \\
\hline VC $(\mathrm{L})$ & 3.84 & 3.69 & 3.84 & 3.53 & & 3.34 \\
\hline $\begin{array}{l}\operatorname{DLCO}(\text { SB } \\
\mathrm{mmol} /(\mathrm{min} . \mathrm{kPa}))\end{array}$ & 9.06 & 4.7 & 4.53 & 4.23 & & 4.57 \\
\hline $\mathbf{R V}(\mathbf{L})$ & 1.46 & 0.8 & 1.29 & 1.16 & & 1.15 \\
\hline $\mathrm{PaO}_{2}\left(\mathrm{FiO}_{2} 21 \%\right)$ & & 86.00 & 91.2 & 85.0 & 90.6 & 90.8 \\
\hline $\mathrm{PaCO}_{2}$ & & 35.80 & 32.3 & 33.7 & 29.3 & 35.9 \\
\hline
\end{tabular}

patient, who had stopped smoking one year before becoming symptomatic, the course of the disease was atypical since it did not develop itself during her smoking period, but perhaps the high amount of pack-years may have contributed to a progressive worsening of her respiratory function. Physiologic changes of the respiratory system are an important consequence of pregnancy itself. Increases in tidal volume and minute volume are due to elevated progesterone levels and carbon dioxide production. The decrease in residual volume, expiratory reserve volume, and functional residual capacity are secondary to cephalic displacement of the diaphragm from the enlarging uterus (9). This might create the potential for regional ventilation-perfusion mismatch and hypoxia. In pregnant LCH patients, studies have described that there is no change in PFT; however, there is a possibility of becoming symptomatic in the last weeks of gestation, just as it happened with our patient $(5,8)$.

In literature, most deliveries occur through a cesarean section; however, vaginal labor is not contraindicated depending on the patient's clinical status $(5,10)$. In our case, vaginal delivery was chosen due to the relative stability of the patient as well as there being no signs of fetal distress and an intentional quicker patient recovery. Placing an epidural catheter in the initial stage of labor and confirming its correct positioning allowed for a preventive measure in the event of an emergent intervention, thus avoiding general anesthesia. Also, reducing the pain stimulus allowed the patient to have more control over her respiration, and this contributed to successful vaginal delivery. Being able to titrate the anesthetic, generates sufficient analgesia while avoiding a negative impact on both hemodynamic stability and oxygen exchange was our major goal for this patient (11). In these patients, preparation and a proper follow-up are key to ensure a better outcome not only for the mother but also for the child (10).

\section{Footnotes}

Authors' Contribution: Study concept and design: IM. Acquisition of data: DV and IM. Analysis and interpretation of data: IM and MC. Drafting the manuscript: MC and IM. Critical revision of the manuscript for important intellectual content: AR. Study supervision: AR.

Conflict of Interests: The authors declared no conflict of interest.

Funding/Support: Not applicable.

Informed Consent: Written informed consent was obtained from the patient before the publication of this paper. The patient's information remained confidential.

\section{References}

1. Tillotson CV, Patel BC. Langerhans Cell Histiocytosis. Treasure Island (FL): StatPearls Publishing; 2020.

2. Brito MDD, Martins Â, Andrade J, Guimarães J, Mariz J. Histiocitose de Largerhans no Adulto: Experiência de Dois Hospitais Portugueses. Acta Med Portuguesa. 2014;27(6). doi:10.20344/amp.5360.

3. Islinger RB, Kuklo TR, Owens BD, Horan PJ, Choma TJ, Murphey MD, et al. Langerhans' cell histiocytosis in patients older than 21 years. Clin Orthop Relat Res. 2000;(379):231-5. doi:10.1097/00003086-20001000000027. [PubMed: 11039811].

4. Girschikofsky M, Arico M, Castillo D, Chu A, Doberauer C, Fichter J, et al. Management of adult patients with Langerhans cell histiocytosis: recommendations from an expert panel on behalf of Euro-HistioNet. Orphanet J Rare Dis. 2013;8:72. doi: 10.1186/1750-1172-8-72. [PubMed: 23672541]. [PubMed Central: PMC3667012].

5. Sharma R, Maplethorpe R, Wilson G. Effect of pregnancy on lung function in adult pulmonary Langerhans cell histiocytosis. J Matern Fetal Neonatal Med. 2006;19(1):67-8. doi: 10.1080/14767050500333835. [PubMed: 16492595]. 
6. Ananthakrishnan S. Diabetes insipidus in pregnancy: etiology, evaluation, and management. Endocr Pract. 2009;15(4):377-82. doi: 10.4158/EP09090.RA. [PubMed: 19454377].

7. Poorvu PD, Frazier AL, Feraco AM, Manley PE, Ginsburg ES, Laufer MR, et al. Cancer Treatment-Related Infertility: A Critical Review of the Evidence. JNCI Cancer Spectr. 2019;3(1):pkz008. doi: 10.1093/jncics/pkz008. [PubMed: 31360893]. [PubMed Central: PMC6649805].

8. Radzikowska E, Wiatr E, Franczuk M, Bestry I, Roszkowski-Sliz K. Lung Function in Pregnancy in Langerhans Cell Histiocytosis. Adv Exp Med Biol. 2018;1023:73-83. doi:10.1007/5584_2017_72. [PubMed: 28744781].

9. Mehta N, Chen K, Hardy E, Powrie R. Respiratory disease in preg- nancy. Best Pract Res Clin Obstet Gynaecol. 2015;29(5):598-611. doi: 10.1016/j.bpobgyn.2015.04.005. [PubMed: 25997564].

10. Fuks L, Kramer MR, Shitrit D, Raviv Y. Pulmonary Langerhans cell histiocytosis and diabetes insipidus in pregnant women: our experience. Lung. 2014;192(2):285-7. doi: 10.1007/s00408-014-9559-8. [PubMed: 24519262].

11. Broscheit J, Eichelbroenner O, Greim C, Bussen S. Anesthetic management of a patient with histiocytosis $\mathrm{X}$ and pulmonary complications during Caesarean section. Eur J Anaesthesiol. 2004;21(11):919-21. doi 10.1017/s0265021504240285. [PubMed: 15717713]. 